\title{
SEISMIC PERFORMANCE OF PRECAST COLUMNS CONNECTED WITH TWO DIFFERENT CONNECTION MODES
}

\author{
Chuanlin Wang \\ Department of Civil and Environmental Engineering, Shantou University, Guangdong Engineering \\ Center for Structure Safety and Health Monitoring, Shantou, No. 243, Daxue Road, 515063, \\ China; clwang@stu.edu.cn
}

\begin{abstract}
The precast reinforced concrete building is made of precast components connected at the joints via reliable connection approaches. In this paper, experiments on two connection modes, i.e. corrugated pipe confined with spiral stirrup connection and steel sleeve connection, were carried out. The experimental tests consisted of six specimens, including one cast-in-situ specimen, three precast specimens using steel sleeve connection and two precast specimens using corrugated pipe confined with the spiral stirrup. The influence of artificially unbonded length at the connection joint was also studied. All specimens were tested under low-frequency cyclic repeated loading to analyze their seismic performance under different connection modes. The experimental results showed that the precast columns using the two proposed connections have a similar or even better seismic performance compared with the cast-in-situ column. The installation of proper unbonded treatment on the longitudinal reinforcement in the connection is beneficial in improving the seismic performance of precast columns and the length of 5 times of the longitudinal reinforcement's diameter is recommended.
\end{abstract}

\section{KEYWORDS}

Precast column, Steel sleeve connection, Corrugated pipe confined with spiral stirrup, Seismic behaviour Artificially unbonded treatment

\section{INTRODUCTION}

The precast concrete structure components are created, and cured off-site then lifted to their final resisting place and assembled securely at the construction site. The advantages of the precast building compared with cast-in-situ buildings include improving construction quality, increased construction speed, and saving material consumption and little impact on the environment [1,2]. The main shortcomings of precast structures are high-cost, lack of integrity and discontinuity of the connections. Therefore, the connections' quality and reliability are often suspected and doubted by consumers and some engineers. However, as defined in ACI 550 [3], if with emulative connections, the precast structure can achieve equivalent or even better seismic performance compared to the cast-in-situ structure. Biondini et al. [4,5] pointed out that the early brittle failures of the joint connections of precast frames can be avoided by a proper capacity design. Therefore, it is necessary to ensure that the load-bearing members, especially the connection joint in the precast structure have enough strength and energy dissipation capacity. The seismic design criteria for precast frame structures have extensively considered the role of the connections, which were further developed based on a series of European research projects (Ecoleader 2001-2003, Growth 2002-2006) over the last two decades [4-10]. In 2012, the European Commision has supported a project called SAFECLADDING research to investigate the design solutions for precast structures [11]. 


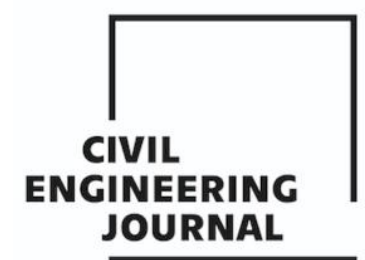

Article no. 46

THE CIVIL ENGINEERING JOURNAL 3-2021

The two main types of precast reinforced concrete structure are precast shear wall system and precast frame system. As stated previously, no matter which type of structure, the critical problem is to guarantee the safety and reliability of the splice that connects the precast components. To develop an economical, simple and reliable connection, many researchers and engineers have proposed various connection approaches for the precast system, and the seismic behaviour of the precast components and the joint connection methods have been comprehensively studied [12-18]. Grouted sleeve, corrugated metal pipe, grouting-anchoring lap splice and steel sleeve are the most commonly used ones, illustrated in Figure 1. High strength cementitious grout is later poured into the reserved holes for these connections to provide connecting strength.

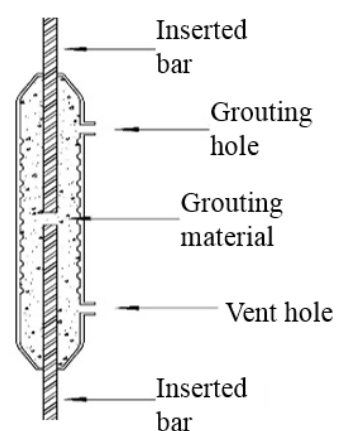

(a)

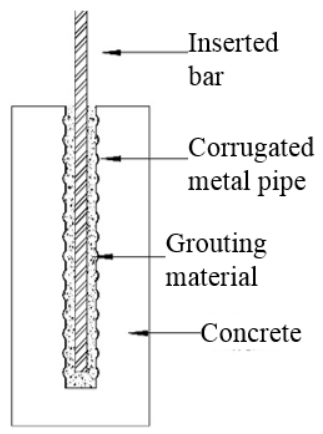

(b)

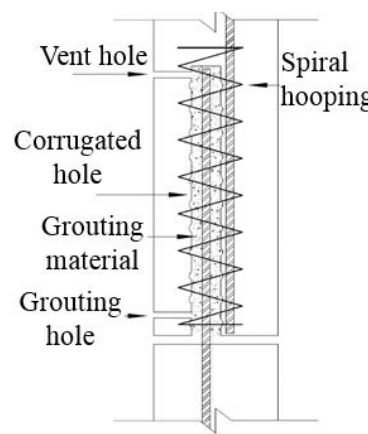

(c)

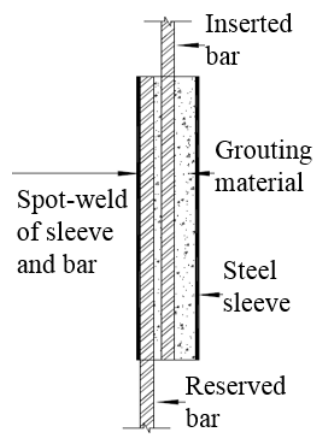

(d)

Fig. 1 - Different types of connection: (a) Grouted sleeve; (b) Grouting anchoring; (c) Corrugated pipe confined with spiral hoop; (d) Steel sleeve

Grouted sleeve connection (Figure 1 (a)) has been widely used in precast structures because of its high strength and easy implementation $[19,20]$. The precast components are connected by inserting the bars into the pre-embedded grouted sleeves, and then high-strength grouting material is injected into the sleeve. The typical failure type of this kind connection includes bar pull-out, bar fracture and sleeve fracture [21]. Though the grouted sleeve can effectively transfer the rebar stress, it is much more expensive than other types of connection, and its high precision and difficulty in processing have limited its widespread use [18]. Compared with grouted sleeve, grouting anchoring in a corrugated pipe (Figure 1 (b)) is much cheaper. However, the anchoring length should be considered to guarantee the mechanical performance of the connecting joint [22]. Therefore, the inserted bars are often lapped with the embedded bars, and spiral stirrup is proposed to install around the pipe to provide confinement and improve the robustness of the splices. It is strictly required that the newly formed connection joint must have a more robust performance than the longitudinal reinforcement no matter in what conditions [23], which means the corrugated pipe confined with spiral stirrup should fail later than the reinforcements it connected. Belleri and Riva [24] conducted an experimental study on the precast columns connected by corrugated steel grouting sleeve, and the results showed that this type of connection could effectively transfer steel stress. In the work of Jiang et al. [25], pull-out tests of precast concrete specimens with rebar embedded in corrugated pipe confined with spiral stirrup were carried out. The experimental results proved that this type of connection is simple, reliable and economical. Steel sleeve or metal duct grouted connector is often used in New Zealand to connect precast concrete components to their foundations $[2,26]$. The merit of using this type of connection is simple, but it also displayed the vulnerability, which has been revealed in several past studies [27,28]. In the work of Kim [28], the grouted metal duct connection presented a poor performance compared with cast-in-situ structure due to the pull-out of the longitudinal bar from the 


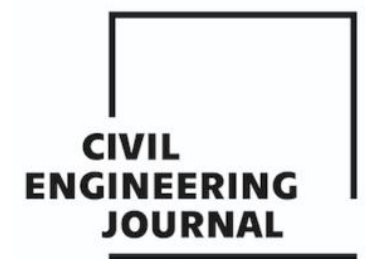

Article no. 46

THE CIVIL ENGINEERING JOURNAL 3-2021

metal duct. In the research of Riva [27], the energy dissipation and failure displacement were depended on the level of confinement provided to the connections as the column stiffness will decrease if large cracks occurred and spread around the metal ducts. As the corrugated pipe connection and steel sleeve connection is cheap and straightforward; therefore, it is necessary to investigate their seismic performance under different conditions, thus developing a safer and more reliable connection. In this research, the connection modes of corrugated pipe confined with spiral stirrup and steel sleeve are experimentally investigated and compared in the aspects of bearing capacity, fracture mode, ductility and energy dissipation capacity under low-frequency cyclic load.

Furthermore, Pandey and Mutsuyoshi [29] found that the installation of unbonded longitudinal reinforcement in the reinforced concrete structure improves its seismic performance. Wu et al. [30] made the same conclusion that some unbonded longitudinal bars in the column foot can enhance the column's seismic performance. Therefore, the influence of artificially unbonded treatment on the seismic performance of the precast column was also investigated in this research. To develop an easy and cheap construction system in the precast structure, the reserved hole will be placed on the foundation, and then the hole will be filled with high-strength grouting filler. After that, the extended longitudinal reinforcement in the precast concrete column will be inserted into the corrugated pipe and steel sleeve to make a rigid connection.

\section{EXPERIMENTAL PROGRAM}

\section{Test specimens}

In this research, six inverted T-shaped reinforced concrete specimens were cast, including a cast-in-situ reinforced concrete column, three precast $\mathrm{RC}$ columns with steel duct connection and two precast $\mathrm{RC}$ columns with corrugated pipe confined by spiral stirrup connection, which was then tested to determine their seismic performance. The precast columns were designed following the law of emulative connection suggested in the ACI 550 [3]. Specifically, the influence of unbonded length at the column base and joint connection type are considered and investigated in this research. Due to the limitation of experimental condition, i.e. the equipment in this experiment cannot provide too high axial pressure. Therefore, the appropriate column cross-section size will be chosen based on a $1 / 2$ scale model experiment. The effect and efficiency of steel sleeve connection and corrugated pipe confined with spiral stirrup can be qualitatively investigated and obtained through the model test. Hence, the column's dimensions are $200 \mathrm{~mm} \times 200 \mathrm{~mm}$, and the net height of the column is $1100 \mathrm{~mm}$. The horizontal loading point is located at $1000 \mathrm{~mm}$ from the base of the column. Four longitudinal reinforcements with a diameter of $12 \mathrm{~mm}$ are placed in the column. The foundation's dimension is $1200 \mathrm{~mm} \times 340 \mathrm{~mm} \times 360 \mathrm{~mm}$, four rebars with a diameter of $16 \mathrm{~mm}$ and four rebars with a diameter of $8 \mathrm{~mm}$ are used. The outer diameter and thickness of the steel duct are $50 \mathrm{~mm}$ and $3 \mathrm{~mm}$, respectively. The diameter of the corrugated pipe is $40 \mathrm{~mm}$. The length of the steel duct and corrugated pipe are both $300 \mathrm{~mm}$. Based on the previous research carried out on the anchorage length, $300 \mathrm{~mm}$ is enough to splice the rebars, though it is smaller than the Chinese Standard $(355 \mathrm{~mm})$ and British Standard $(340 \mathrm{~mm})$. The specimen's schematic illustration is shown in Figure 2, and the specimen details of precast columns are displayed in Figure 3.

The precast components were cast and cured first, and then the reserved hole was filled with high-strength grouting material. After that, the column and the foundation would be connected by inserting the extended rebars into the reserved holes. The grouting material would be spilt out and tiled on the surface between the column and the foundation, which exactly filled the gap between them and made a rigid connection. The detailed manufacturing process is illustrated in Figure 4. Furthermore, the artificially unbonded treatment is made by separating the longitudinal reinforcements from the concrete at the column base using insulating tape, shown in Figure 4 (a). The specific operation is carried out by binding the insulating tape around the reinforcement at the height from $300 \mathrm{~mm}$ to $360 \mathrm{~mm}$. Based on the previous research, the unbonded treatment of $5 \mathrm{~d}$ and 
$10 \mathrm{~d}$ ( $\mathrm{d}$ is the longitudinal bar's diameter) is considered. The details of each specimen are summarized in Table 1.

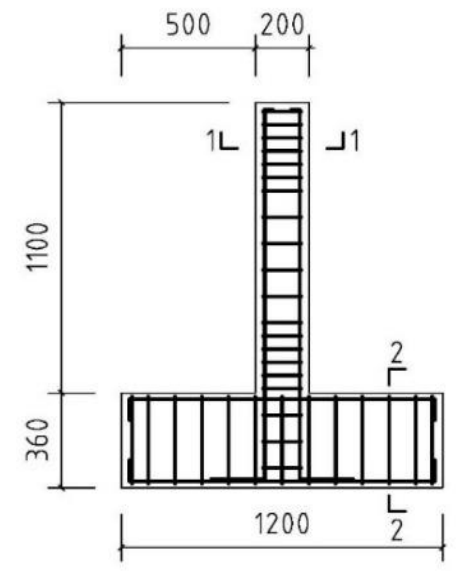

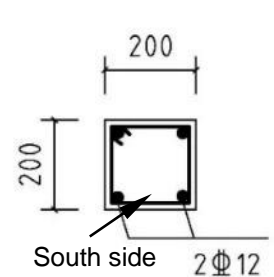

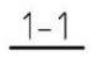

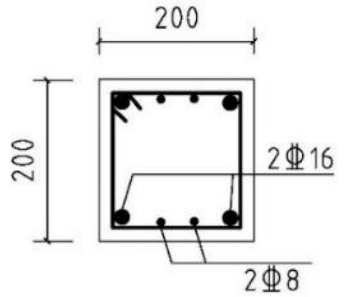

$\underline{2-2}$

Fig. 2 - Specimen details
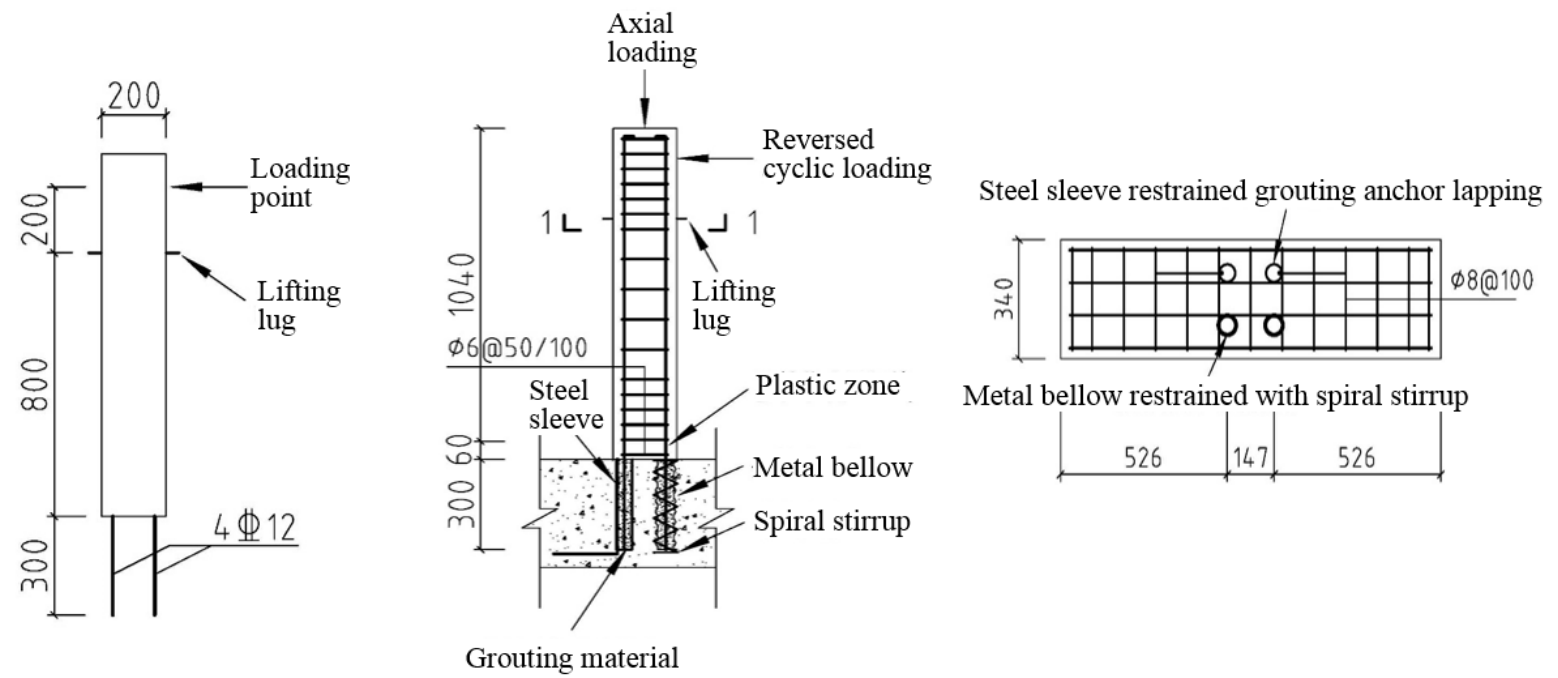

Metal bellow restrained with spiral stirrup

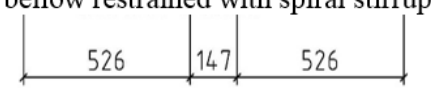

Fig. 3 - Specimen details of precast columns 


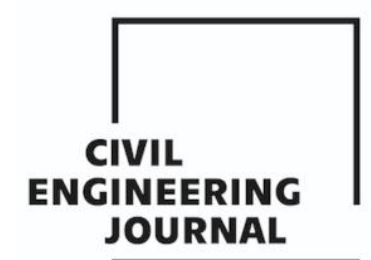

Article no. 46

ENGINEERING JOURNAL

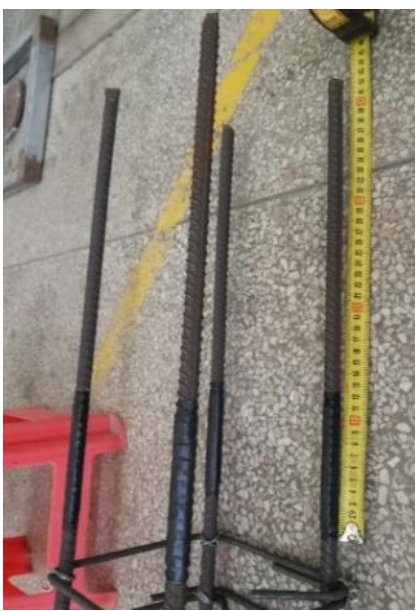

(a)

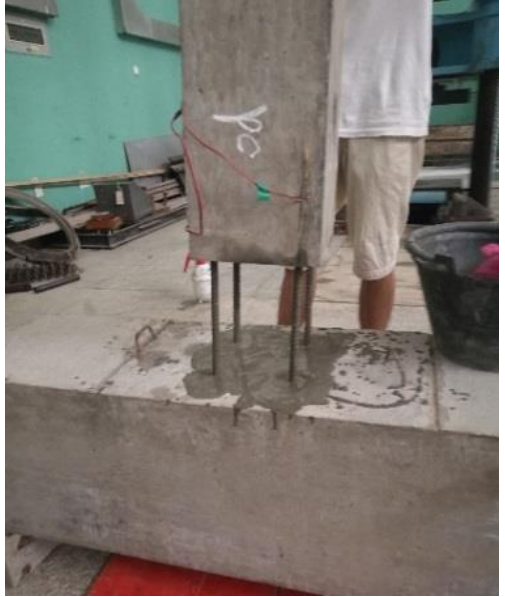

(b)

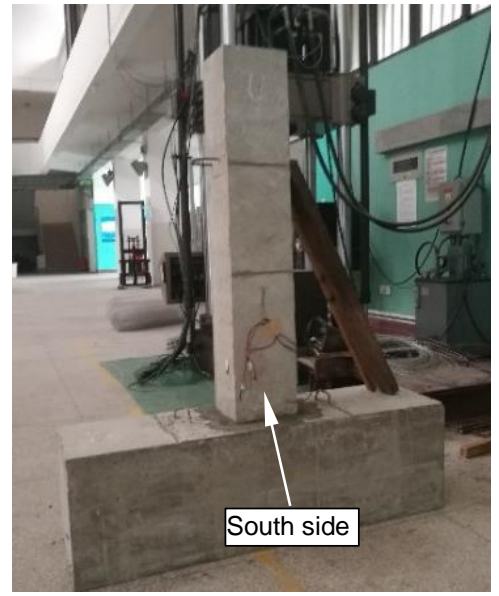

(c)

Fig. 4 - Manufacturing process of the precast column: (a). Install of plastic hinge zone; (b). Hoisting of the column; (c). The precast column

Tab. 1: Experimental details of all specimens

\begin{tabular}{|c|c|c|c|c|c|}
\hline No. & $\begin{array}{c}\text { Longitudinal } \\
\text { rebar }\end{array}$ & $\begin{array}{c}\text { Reinforcement } \\
\text { ratio }\end{array}$ & $\begin{array}{c}\text { Axial force } \\
(\mathrm{KN})\end{array}$ & $\begin{array}{l}\text { Length of } \\
\text { plastic hinge }\end{array}$ & Connection type \\
\hline $\mathrm{XJ}-1$ & $4 \phi 12$ & 1.13 & 458 & $0 d$ & Cast-in place connection \\
\hline YG-2 & $4 \phi 12$ & 1.13 & 458 & $0 \mathrm{~d}$ & \multirow{3}{*}{ Steel sleeve connection } \\
\hline YG-3 & $4 \phi 12$ & 1.13 & 458 & $5 d$ & \\
\hline YG-4 & $4 \phi 12$ & 1.13 & 458 & $10 \mathrm{~d}$ & \\
\hline $\mathrm{YL}-1$ & $4 \phi 12$ & 1.13 & 458 & $0 d$ & \multirow{2}{*}{$\begin{array}{l}\text { Corrugated pipe confined } \\
\text { with spiral stirrup connection }\end{array}$} \\
\hline YL-2 & $4 \phi 12$ & 1.13 & 458 & $5 d$ & \\
\hline
\end{tabular}

\section{Material properties}

The concrete samples were collected during the construction of specimens, and the grouting samples were taken after the grouting material poured into the reserved hole. The dimensions of the concrete samples are $100 \mathrm{~mm} \times 100 \mathrm{~mm} \times 100 \mathrm{~mm}$, and the dimensions of grout cube samples are $50 \mathrm{~mm} \times 50 \mathrm{~mm} \times 50 \mathrm{~mm}$. They were cast and cured at the same condition with the column specimens. The reinforcement samples were tested as well. The specific properties of the materials in terms of mean value are summarized in Tables 2 and 3.

Tab 2: Compressive strength of concrete and grout

\begin{tabular}{|c|c|}
\hline Material & Compressive strength (MPa) \\
\hline Concrete & 55.74 \\
\hline Grout & 63.33 \\
\hline
\end{tabular}


Tab 3: Steel mechanical properties

\begin{tabular}{|l|l|l|l|l|}
\hline $\mathrm{d}(\mathrm{mm})$ & $\mathrm{E}(\mathrm{GPa})$ & $f_{y}(\mathrm{MPa})$ & $f_{u}(\mathrm{MPa})$ & $\varepsilon_{u}(\%)$ \\
\hline 12 & 210 & 458.3 & 587.6 & $21 \%$ \\
\hline
\end{tabular}

\section{Test setup}

This study's experimental equipment includes an automatic data collecting system, a hydraulic jack, and a hydraulic actuator. The hydraulic jack was mounted on top of the column to provide axial compression. A pulley was installed between the rigid steel frame and the hydraulic jack to reduce friction between them. The hydraulic actuator was used to provide horizontal reversed-cyclic loading. Steel plates were placed around the column at the loading point to reduce stress concentration and make a good connection between the actuator and the column. After the specimen was lifted and placed in the right position, the foundation would be mounted to the rigid floor by steel anchors. After that, the axial compression force and the horizontal loading would be applied, respectively. The test setup is displayed in Figure 5.

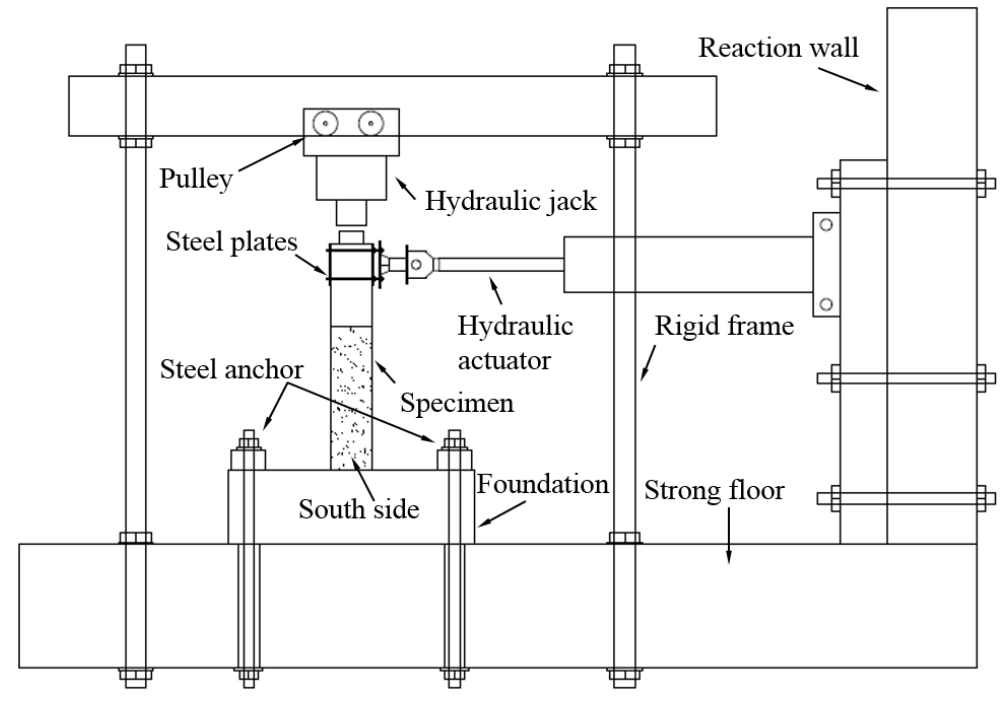

Fig 5 - Schematic illustration of the test setup

\section{Loading procedure}

In this study, low-frequency reversed cyclic loading protocol based on the Chinese Standard JGJ101 [31] was carried out at the Shantou University Structure's Laboratory in Shantou, China. In this standard, dual control of load-displacement is recommended for the loading procedure under low-frequency reversed cyclic loading. The standard recommends using multistage loading before crack and keeps loading with smaller increments before reaching its cracking stage. The loading procedure will be changed to displacement-controlled after cracks occurred. At the beginning of the test, a hydraulic jack was applied on the top of the column, and an axial load of $458 \mathrm{kN}$ was provided. The horizontal load should be applied based on its theoretical cracking loading. In this study, the theoretical cracking loading is about $38 \mathrm{kN}$. The $38 \mathrm{kN}$ will be applied on the column with three increments, and each increment will be carried out in three reversed cycles. After the cracks occurred on the bottom of the column, the displacement $\Delta$ will be recorded, and displacement-controlled loading protocol will then be carried out. The increment of the displacement-controlled loading will be $\Delta$, and each increment will be repeated three times. The 


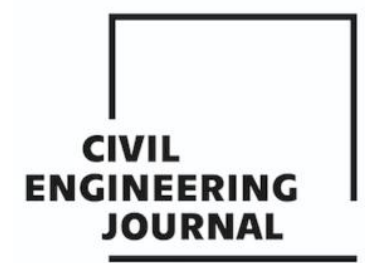

Article no. 46

THE CIVIL ENGINEERING JOURNAL 3-2021

specimen will be termed as failed when the residual lateral load reached $80 \%$ of the peak load, and the loading process will be terminated. The lateral loading protocol is shown in Figure 6.

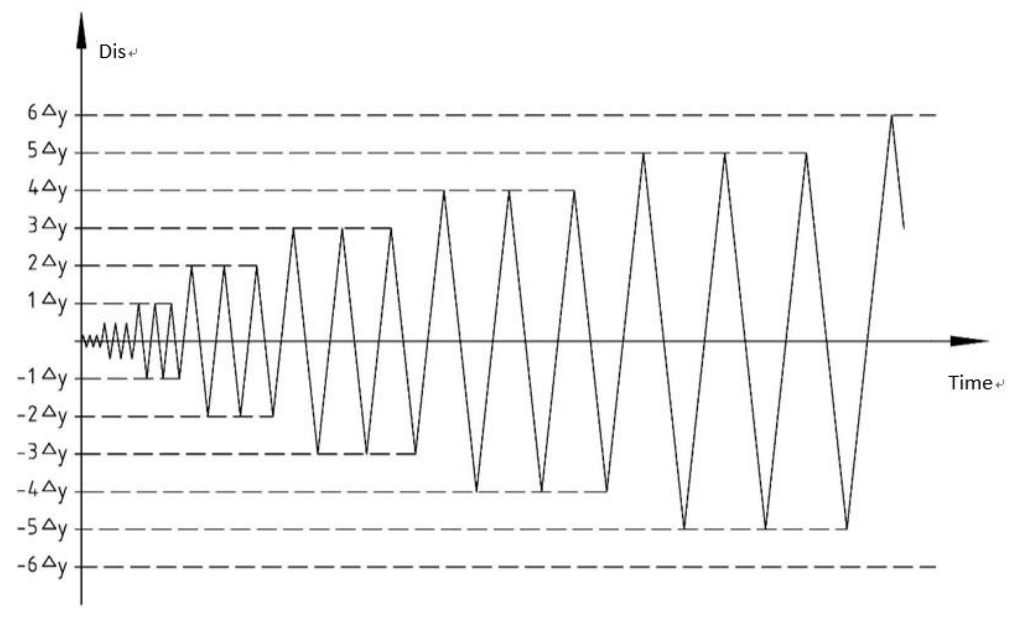

Fig. 6 - Lateral loading protocol

\section{EXPERIMENTAL RESULTS}

\section{Crack patterns and failure modes}

As the crack kept developing at different lateral displacement, the crack patterns and failure modes were recorded when the lateral displacement reached $5 \Delta$ to compare all specimens' crack patterns and failure modes. The specimens' crack patterns and failure modes are displayed in Figure 7, where all specimens are characterized by flexural failure. Under the low-frequency reversed cyclic loading, the development and progress of all specimens' failure can be grouped into three stages: elastic stage, yielding stage and failure stage. In the elastic stage, with the development of horizontal force, the deformation of the specimen increased almost linearly, and the residual deformation was minimal. When it came to the yielding stage, the loading protocol was changed to displacement controlled. With the increase of lateral displacement, the residual deformation accumulated gradually, and more cracks occurred on all sides of the column. There began to appear crushing and spalling at the base of the column. In the failure stage, the column base had been crushed, and later quit working entirely. The crack patterns of all specimen appeared quite similar. At the beginning of loading, horizontal penetrating cracks occurred on the east and west side (the loading direction) of the column at the location where stirrups were installed, and they kept propagating and reached to the south side. Short and horizontal cracks first appeared on the south side. With the development of deformation, the short and horizontal cracks on the south side started to develop diagonally and kept propagating until they intersected at the central place of the south side in the form of "X", displayed in Figures 7 (a), (c) and (e). As the bending moment reached the maximum at the column foot; therefore, the concrete at this place reached the ultimate compressive strain and was continually crushed and peeled off. The whole failure mode of specimens is typically large-eccentric compression failure. 


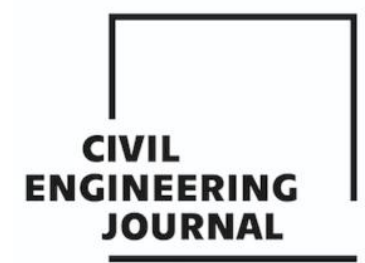

Article no. 46

THE CIVIL ENGINEERING JOURNAL 3-2021

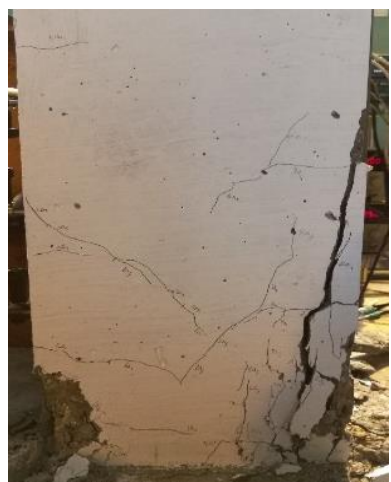

(a) $\mathrm{XJ}-1$ (South side)

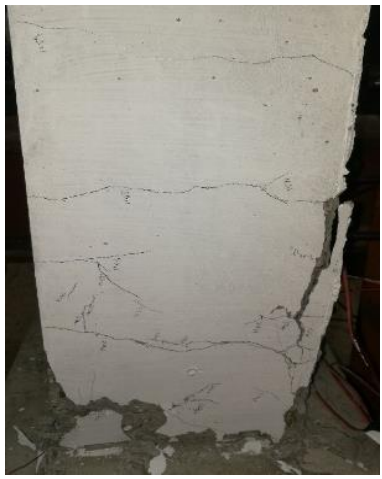

(d) YG-3 (East side)

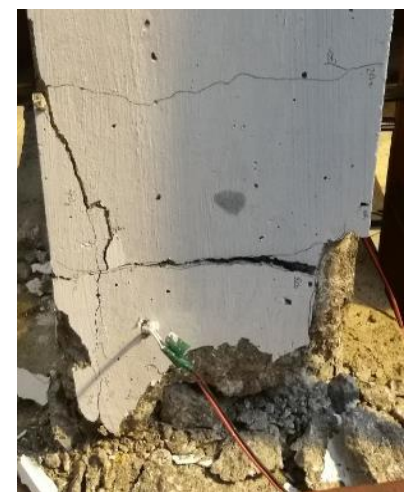

(b) $\mathrm{XJ}-1$ (East side)

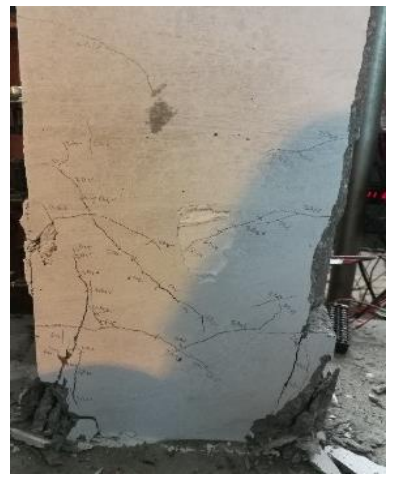

(e) YL-2 (South side)

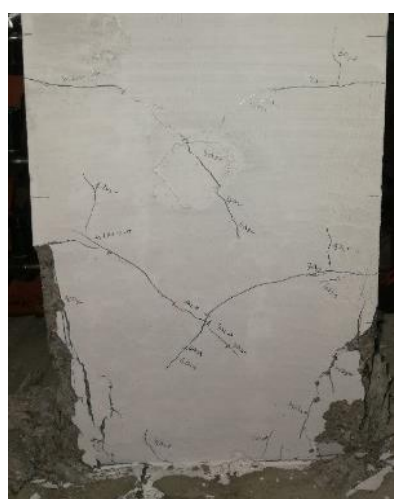

(c) YG-3 (South side)

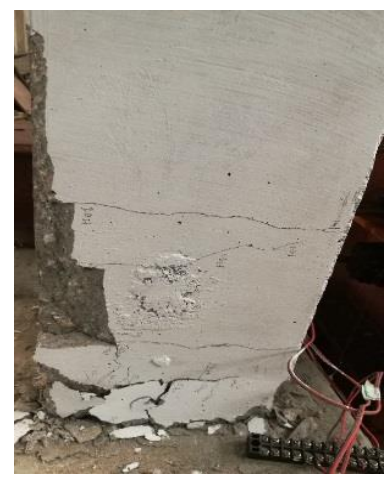

(f) $Y L-2$ (East side)

Fig. 7 - Crack patterns and failure mode of the specimens at displacement of $5 \Delta$

\section{Hysteresis loops and skeleton curves}

The hysteresis loops and skeleton curves of each specimen are illustrated in Figures 8 and 9 , respectively. Hysteresis loop describes the relationship between the cyclic load and lateral displacement, reflecting the seismic performance. Figure 8 displays the development and evolution of the hysteresis loops, which are quite similar for all specimens. Under the load-controlled stage, there was no crack. Therefore, the specimens can be treated as a rigid body, and the rigidity barely changed. However, tiny and hairy cracks were produced inside the concrete, and minimal residual deformation still existed after unloading horizontal force, thus forming a tiny hysteresis loop. When it came to the displacement-controlled loading stage, concrete started to crack as it surpassed the ultimate strength. At the beginning of the displacement-controlled loading stage, although the concrete has cracked, and a small part was crushed and spalled, but it still kept working, and the stiffness of the specimens remained unchanged. In this stage, the peak horizontal load of the specimens raised with the increase of displacement, and the growth rate of peak horizontal load decreased with the improvement of displacement. At the end of the displacement-controlled loading stage, large pieces of concrete were crushed and peeled off, the stiffness declined rapidly, and the peak horizontal load decreased accordingly. Most of the hysteresis loops of the specimens are bow-shaped and have some pinching phenomenon. However, they are also fully shaped, which shows that the specimens have excellent seismic performance and ductility, and generally conform to the hysteretic curve characteristics of compression-bending members.

Compared of Figures 8 (a), (b) and (e), the hysteretic curve of the precast column YG-2 is fuller, which represents that precast column with steel sleeve connection has the similar bearing capacity, ductility and stiffness degradation with cast-in-situ column, while the seismic performance of the precast column using steel sleeve is better. After comparing the hysteretic curves of precast 


\section{ENGINEERING JOURNAL}

CIVIL

column YL-1 using corrugated pipe confined with spiral stirrup with precast specimen YG-2 and cast-in-situ specimen XJ-1, the area of the hysteresis loop is smaller. Therefore, its seismic performance is worse than the other two types of specimens, though its bearing capacity is higher. The unbonded length of the three specimens displayed in Figures 8 (c), (d), and (f) are $5 d$, 10d and $5 \mathrm{~d}$, respectively. After compared with the ones without installation of unbonded treatment, the hysteretic loop of the specimens with unbonded treatment is fuller, which means using unbonded treatment could improve precast columns' seismic performance.

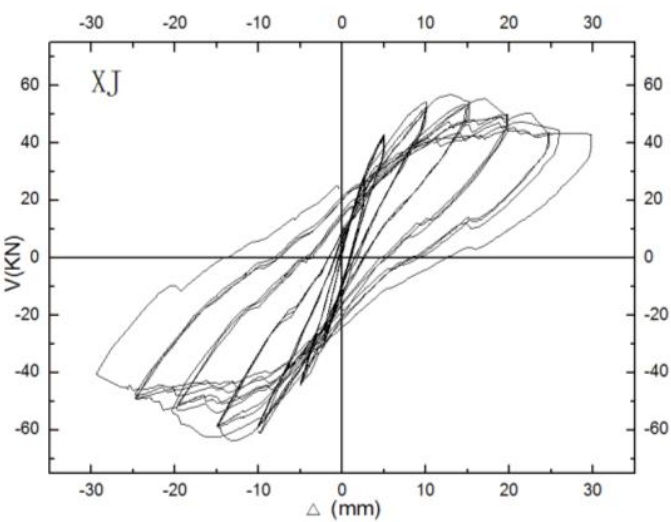

(a) Specimen $X J-1$

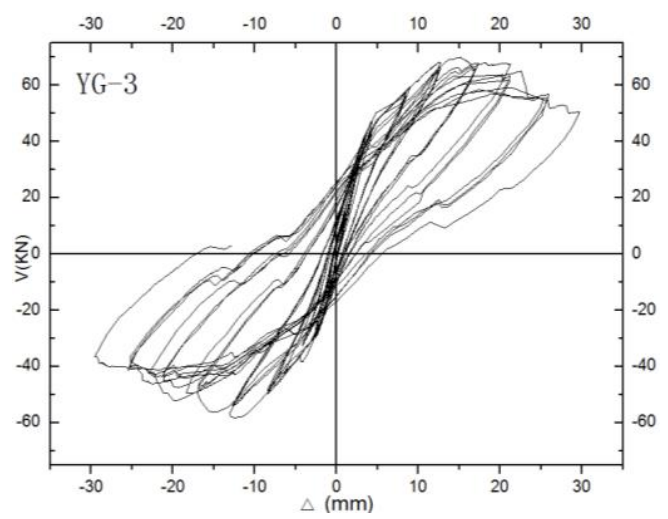

(c) Specimen YG-3

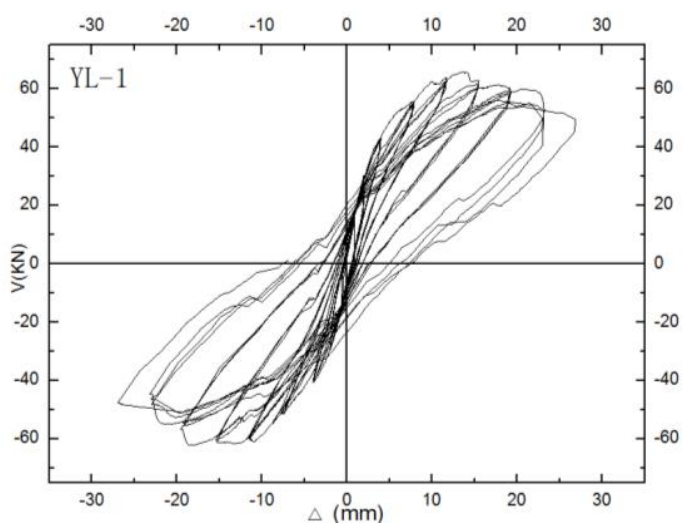

(e) Specimen YL-1

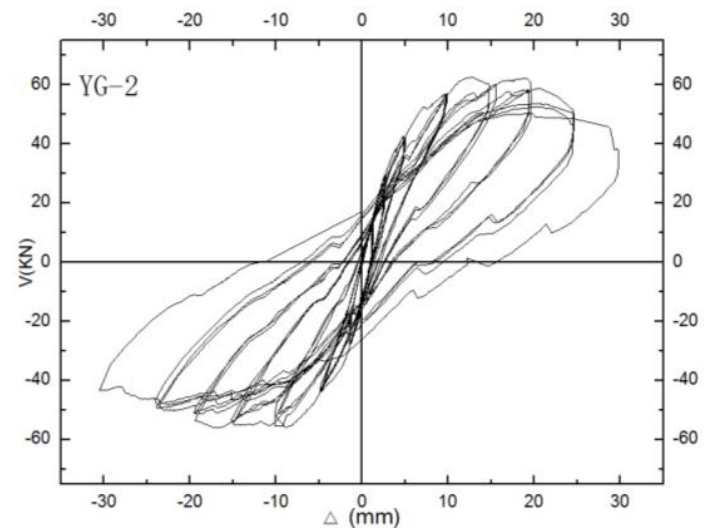

(b) Specimen YG-2

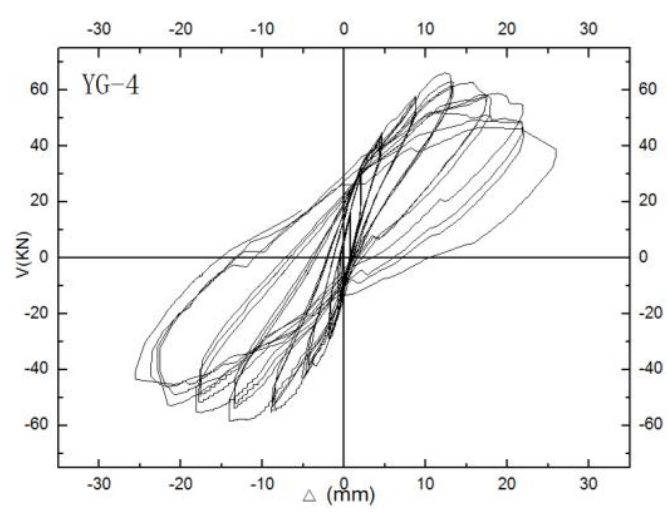

(d) Specimen YG-4

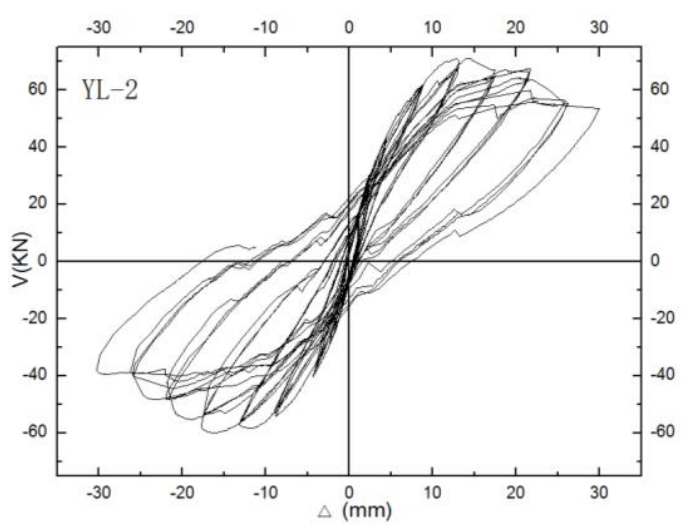

(f) Specimen YL-2

Fig. 8 - Hysteresis loops of the specimens 


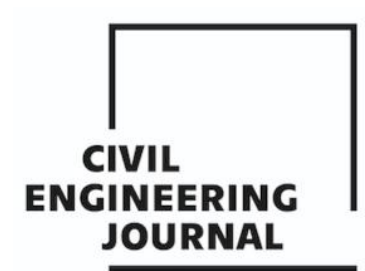

Article no. 46

THE CIVIL ENGINEERING JOURNAL 3-2021

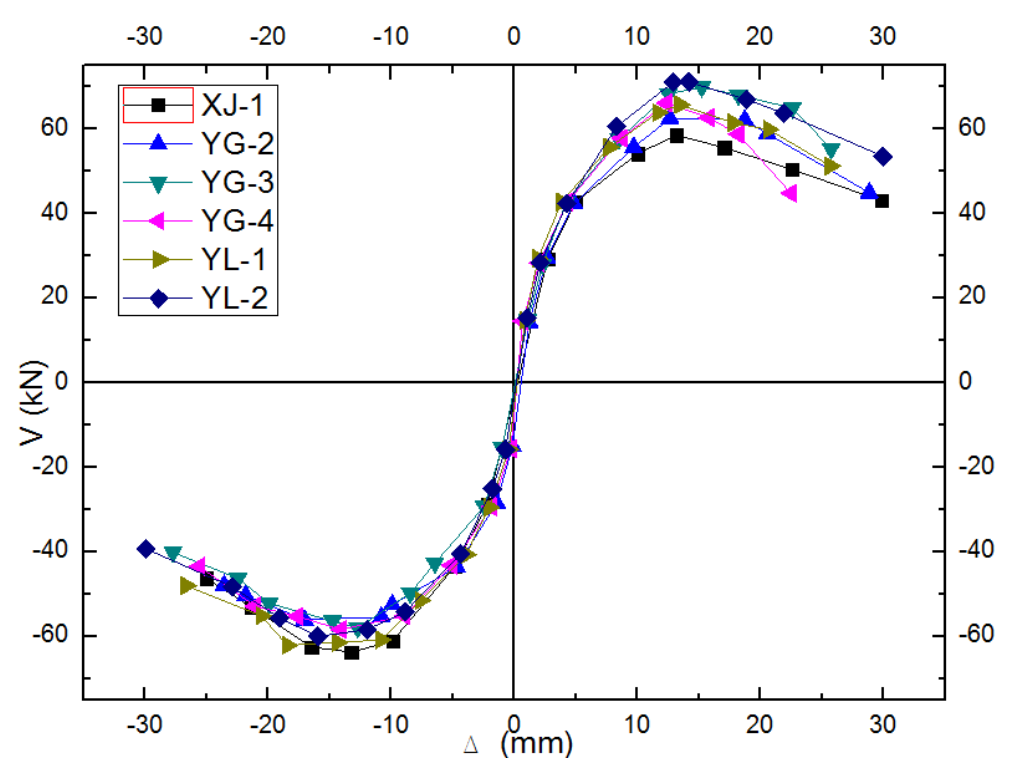

Fig. 9 - Skeleton curve of the specimens

Figure 9 shows that the increase of the horizontal force can be divided into three stages: the elastic stage, yielding stage, and failure stage. At the elastic stage, with the increase of lateral force, the precast column started to crack, and the slope of the skeleton curve began to decline gradually, which indicates that the increased speed of the lateral force slows down. When the lateral force reached the peak stage, the component reached its failure stage. After the peak stage, the lateral force decreased gradually, and more cracks occurred until the component failed finally. From the skeleton curves, it can be concluded that the cast-in-situ specimen and the precast specimens have the similar or even higher lateral resistance, which means that the proposed two types of connection are safe and reliable in connecting precast components. It also can be known that the implementation of artificially unbonded treatment helps improve the precast specimens' bearing capacity.

\section{Bearing capacity and ductility}

Table 4 displays the experimental results of the specimens. The yielding point is determined by the energy equivalence method [32]. The ultimate failure point is regarded when the lateral load dropped to $80 \%$ of the peak load. The ductility is defined by Equation (1), which represents the deformation capacity of the component after yielding.

$$
\mu=\frac{\Delta_{u}}{\Delta_{y}}
$$

Where $\Delta_{u}$ represents the displacement at the ultimate point and $\Delta_{y}$ at the yielding point. Table 4 shows that the precast specimens YG-2 and YL-2 have a similar bearing capacity with cast-in-situ specimen $\mathrm{XJ}-1$, which can be concluded that the two types of connection could be used in the precast construction. Regarding the ductility, specimens $Y G-2$ and $Y L-1$ have been improved by about $13.09 \%$ and $20.32 \%$, respectively, compared with specimen $\mathrm{XJ}-1$, which indicates that these two types of connections could provide better deformation capacity, and the one with spiral stirrup performed much better. After comparing specimens YG-2, YG-3 and YG-4, and comparing specimens YL-1 and YL-2, the utilizing of unbonded treatment is beneficial to the precast specimens. However, it should be noticed that the too-long unbonded treatment could result in worse seismic performance as the ductility of specimen YG-4 (10d) is about $14.5 \%$ smaller than 
Article no. 46

CIVIL

ENGINEERING

JOURNAL

THE CIVIL ENGINEERING JOURNAL 3-2021

the specimen YG-3 (5d). Therefore, the length of $5 d$ ( $d$ is the longitudinal bars' diameters) is recommended in this research.

Tab 4: Test results of all specimens

\begin{tabular}{|c|c|c|c|c|c|c|c|c|c|}
\hline \multirow{2}{*}{$\begin{array}{c}\text { Specime } \\
\mathrm{n}\end{array}$} & \multirow{2}{*}{ Direction } & \multicolumn{2}{|c|}{ Yielding point } & \multicolumn{2}{|c|}{ Critical point } & \multicolumn{2}{|c|}{ Ultimate point } & \multirow[t]{2}{*}{$\mathrm{Vmax} / \mathrm{KN}$} & \multirow[t]{2}{*}{ Ductility } \\
\hline & & $\triangle \mathrm{y} / \mathrm{mm}$ & $\mathrm{Vy} / \mathrm{KN}$ & $\triangle \mathrm{cr} / \mathrm{mm}$ & $\mathrm{Vcr} / \mathrm{KN}$ & $\triangle \mathrm{u} / \mathrm{mm}$ & $\mathrm{Vu} / \mathrm{KN}$ & & \\
\hline \multirow{2}{*}{ XJ-1 } & + & 4.96 & 42.83 & 13.16 & 58.6 & 23.23 & 49.81 & \multirow{2}{*}{63.65} & \multirow{2}{*}{4.43} \\
\hline & - & -4.85 & -43.37 & -13.27 & -63.65 & -20.28 & -54.10 & & \\
\hline \multirow{2}{*}{ YG-2 } & + & 4.84 & 42.43 & 12.63 & 62.58 & 23.96 & 53.19 & \multirow{2}{*}{62.58} & \multirow{2}{*}{5.01} \\
\hline & - & -4.68 & -43.51 & -17.05 & -56 & -23.74 & -47.6 & & \\
\hline \multirow{2}{*}{ YG-3 } & + & 4.19 & 42.7 & 15.21 & 69.96 & 24.38 & 59.47 & \multirow{2}{*}{69.96} & \multirow{2}{*}{5.43} \\
\hline & - & -4.2 & -32.49 & -12.74 & -57.87 & -21.17 & -49.19 & & \\
\hline \multirow{2}{*}{ YG-4 } & + & 4.32 & 42.83 & 12.34 & 66.19 & 20.96 & 56.26 & \multirow{2}{*}{66.19} & \multirow{2}{*}{4.64} \\
\hline & - & -5.12 & -43.1 & -14.09 & -58.27 & -22.64 & -49.53 & & \\
\hline \multirow{2}{*}{ YL-1 } & + & 3.83 & 42.83 & 13.45 & 65.79 & 22.92 & 55.92 & \multirow{2}{*}{65.79} & \multirow{2}{*}{5.86} \\
\hline & - & -3.93 & -40.95 & -18.45 & -62.03 & -22.56 & -52.73 & & \\
\hline \multirow{2}{*}{ YL-2 } & + & 4.26 & 42.43 & 14.15 & 71.16 & 24.49 & 60.486 & \multirow{2}{*}{71.16} & \multirow{2}{*}{5.33} \\
\hline & - & -4.38 & -40.28 & -15.99 & -59.89 & -21.51 & -50.91 & & \\
\hline
\end{tabular}

\section{Stiffness and strength degradation}

Under the low-frequency cyclic loading, the components' stiffness declines with the increase of displacement, which is regarded as the stiffness degradation. The stiffness degradation can be calculated using Equation (2):

$$
K_{i}^{j}=\frac{\left|+V_{i}^{j}\right|+\left|-V_{i}^{j}\right|}{\left|+\Delta_{i}^{j}\right|+\left|-\Delta_{i}^{j}\right|}(2)
$$

Where $+\mathrm{V}_{i}{ }^{j}$ and $-\mathrm{V}_{i}{ }^{j}$ is the positive and negative peak load of the $i^{\text {th }}$ cyclic loading at the $j^{\text {th }}$ displacement step, and $\Delta_{i}{ }^{j}$ is the corresponding displacement. Figure 10 shows the stiffness degradation curve of each test specimen. It can be seen that the stiffness degraded with the increase of displacement, which all have a virtually identical decline trend, which indicates that stiffness deterioration of the two precast connection modes is similar to the cast-in-situ specimen and they both can be used to connect the precast components. 


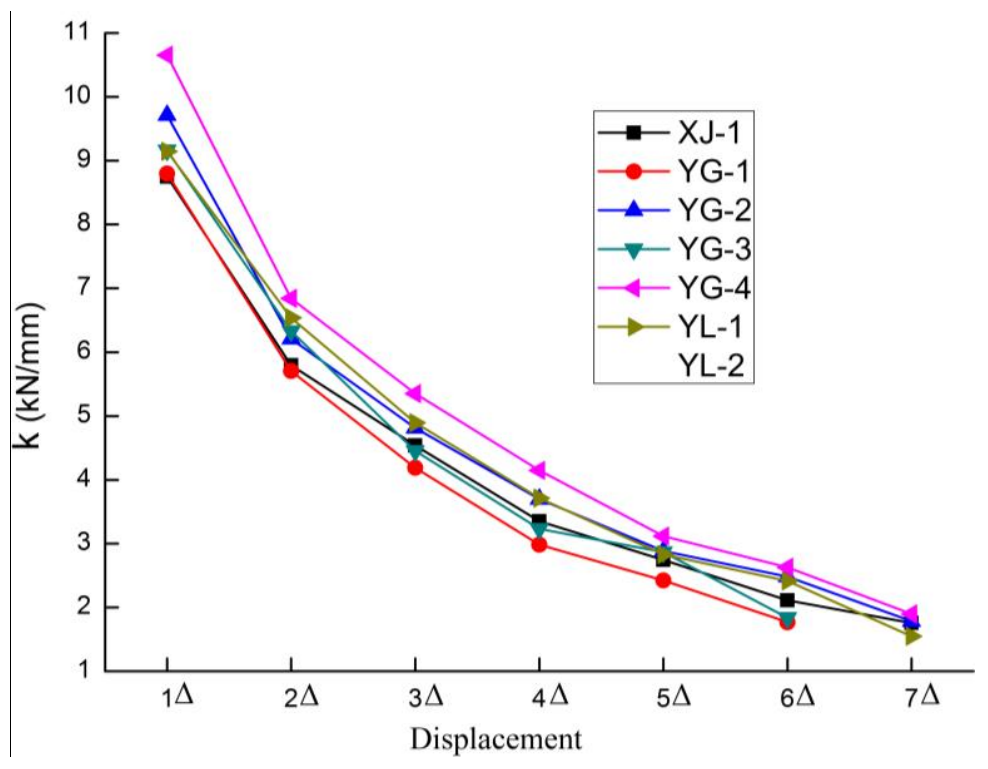

Fig. 10 - Stiffness degradation of the specimens

\section{Energy dissipation}

When the structure is subjected to cyclic loads, the area of the hysteretic loop is the energy dissipated by a cyclic load. Under the same condition, the fuller the hysteretic loop and the larger the area it contains, the higher the structure's energy dissipation capacity and the better the seismic performance. The energy dissipated in each cycle has been calculated, shown in Table 5, and presented in Figure 11. From the figure, the slope of each specimen's cumulative energy dissipation curve increases with the increase of displacement, which indicates that the larger the loading displacement, the faster the specimen's energy dissipation speed. Table 5 shows that precast columns' energy dissipation capacity using both types of connections is equivalent to the cast-in-situ specimens, which proves again that steel duct sleeve and corrugated pipe are confined with spiral stirrups can be used in precast construction. Moreover, the application of certain length unbonded treatment is beneficial in improving the energy dissipation capacity. However, it should be noted that too long unbonded treatment (10d in this research) is harmful to the precast specimens.

Tab 5: Energy dissipation (J)

\begin{tabular}{|l|c|c|c|c|c|c|c|l|}
\hline Specimen & $1 \Delta$ & $2 \Delta$ & \multicolumn{1}{|c|}{$3 \Delta$} & $4 \Delta$ & $5 \Delta$ & $6 \Delta$ & $7 \Delta$ & Total $\times 10^{3}$ \\
\hline XJ-1 & 452.95 & 1260.91 & 2010.43 & 2507.28 & 2795.32 & 3137.15 & $/$ & 12.16 \\
\hline YG-2 & 472.36 & 1239.98 & 1936.98 & 2445.3 & 2738.69 & 3214.44 & $/$ & 12.05 \\
\hline YG-3 & 334.55 & 1082.72 & 1922.06 & 2423.16 & 2861.18 & 3131.28 & 3354.08 & 15.11 \\
\hline YG-4 & 465.82 & 1121.01 & 1840.87 & 2238.65 & 2513.87 & 2531.14 & $/$ & 10.71 \\
\hline YL-1 & 343.82 & 946.09 & 1651.79 & 2244.04 & 2634.34 & 2802.22 & 3177.29 & 13.80 \\
\hline YL-2 & 386.56 & 1125.58 & 1929.65 & 2440.18 & 2791.19 & 3078.06 & 3352.75 & 15.10 \\
\hline
\end{tabular}




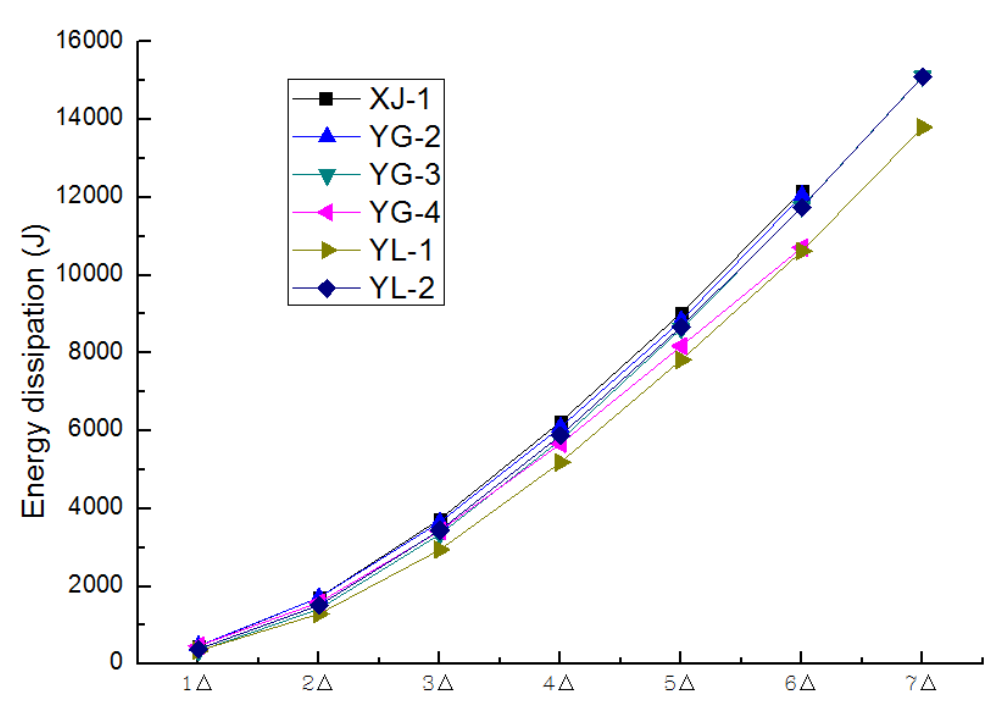

Fig. 11 - Energy dissipation of the specimens

\section{Equivalent Viscous Damping Coefficient}

In "Specification for the seismic test of buildings", the equivalent viscous damping coefficient is defined to analyze the structure's seismic performance, which is calculated through the following equation.

$$
\zeta_{e q}=\frac{1}{2 \pi} \bullet \frac{S_{(A B C+C D A)}}{S_{(O B E+O D F)}}
$$

Where $S_{(A B C+C D A)}$ represents the hysteresis loop area in Figure 12 and $S_{(O B E+O D F)}$ indicates the area of triangles OBE and ODF.

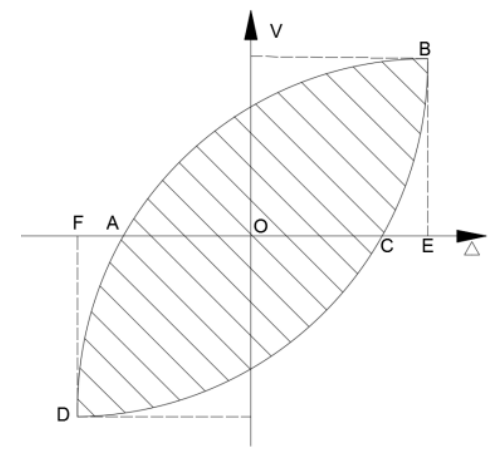

Fig. 12 - Schematic of the load-deformation hysteresis curve

The equivalent viscous damping coefficient of each specimen is calculated using the above equation and the results are displayed in Figure 13. It is known that the curves of equivalent viscous damping coefficients of all specimens show an upward trend, except the specimen of YG4. Moreover, each specimen's equivalent viscous damping coefficient increases slowly with the increase of displacement before yielding. The specimens' equivalent viscous damping coefficient changed slightly after yielding, but the fluctuation range is small. Figure 13 shows that the equivalent viscous damping coefficient of specimen YG-4 is different from others, which indicates that the implementation of $10 \mathrm{~d}$ unbonded treatment on the longitudinal reinforcement in specimen YG-4 is harmful. 
Tab 6: Equivalent viscous damping coefficient $\zeta_{e q}$

\begin{tabular}{|c|c|c|c|}
\hline Specimen & Yielding & Critical & Ultimate \\
\hline XJ-1 & 0.341 & 0.396 & 0.409 \\
\hline YG-2 & 0.368 & 0.444 & 0.422 \\
\hline YG-3 & 0.324 & 0.407 & 0.421 \\
\hline YG-4 & 0.365 & 0.358 & 0.381 \\
\hline YL-1 & 0.338 & 0.404 & 0.390 \\
\hline YL-2 & 0.344 & 0.395 & 0.384 \\
\hline
\end{tabular}

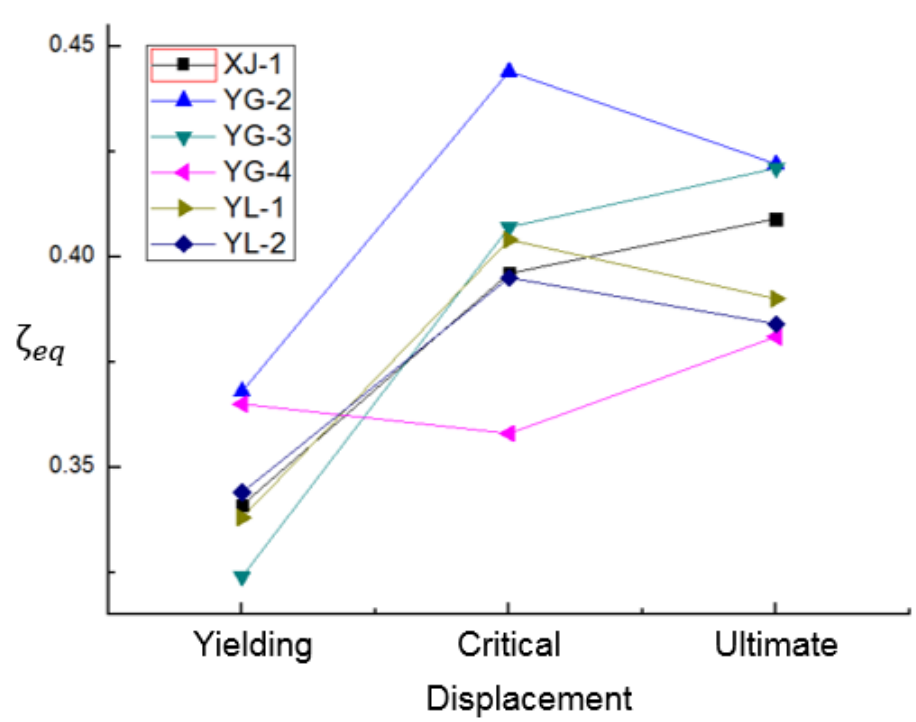

Fig. 13 - Equivalent viscous damping coefficients of the specimens

\section{CONCLUSION}

In this paper, a cast-in-situ reinforced column, three precast columns connected using steel sleeve, and two precast columns connected using corrugated pipe confined with spiral stirrup were tested. The tests were carried out under a combined constant vertical load and low-frequency cyclic horizontal load to determine their seismic performance. The seismic behaviour in terms of failure patterns, bearing capacity, ductility, stiffness, energy dissipation capacity and equivalent viscous damping coefficient are evaluated comprehensively. Based on the experimental results, the following conclusions can be made:

(1) The failure modes of precast column specimens and cast-in-situ column specimens are basically the same. At the beginning of loading, horizontal penetrating cracks occurred on the east and west side of the column at the location where stirrups were installed. On the south side of the column, the crack appeared in the form of "X". The concrete at the column base was crushed and peeled off. The whole failure mode of specimens belongs to large eccentric compression failure.

(2) The precast specimens using both types of connection presented a similar or even better seismic performance compared with the cast-in-situ column in terms of bearing capacity, ductility, energy dissipation and equivalent viscous damping coefficient.

(3) For both types of precast column specimens, the application of the artificially unbonded treatment on the longitudinal reinforcement could improve the bearing capacity, ductility, energy 


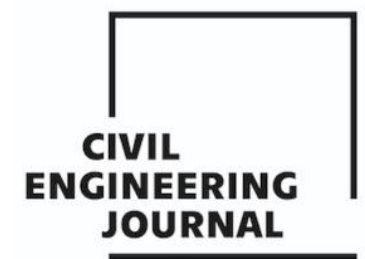

Article no. 46

THE CIVIL ENGINEERING JOURNAL 3-2021

dissipation as well as equivalent viscous damping coefficient. However, it is harmful if the unbonded length is too large. The recommended length of unbonded treatment in this paper is five times of the longitudinal reinforcement's diameter.

(4) The connection type of steel sleeve and corrugated pipe confined with spiral stirrup both can effectively connect precast components, and the seismic performance of the precast columns using the above two connection modes are much better than that of cast-in-situ column. Therefore, these two connection modes can be applied in practical precast structures.

In a further study, the same connection method will be used to test the specimens with larger cross-section. Moreover, the unbonded treatment of different lengths will be considered to determine the most suitable and beneficial unbonded length. Besides, some energy-dissipating steel bars will be installed at the joints to improve the prefabricated structures' seismic performance.

\section{ACKNOWLEDGEMENTS}

This research was supported by the Shantou University Research Start-Up Fund (NFT17011). The authors gratefully acknowledge its financial support.

\section{REFERENCES}

[1] Xu, L., Pan, J., and Cai, J., 2019. Seismic performance of precast RC and RC/ECC composite columns with grouted sleeve connections. Engineering Structures, Vol. 188:104-110

[2] Seifi, P., Henry, R., and Ingham, J., 2019. In-plane cyclic testing of precast concrete wall panels with grouted metal duct base connections. Engineering Structures, Vol.184: 85-98

[3] $\mathrm{ACl} 550 ., 2009$. Guide to emulating cast-in-place detailing for seismic design of precast concrete structures, Farmington Hills, MI, USA.

[4] Biondini, F., and Toniolo, G., 2009. Probabilistic calibration and experimental validation of seismic design criteria for one storey concrete frames. J Earthq Eng, Vol. 13, No. 4: 426-462.

[5] Biondini, F., Toniolo, G., and Tsionis, G., 2010. Capacity design and seismic performance of multistorey precast structures. Eur J Environ Civil Eng, Vol. 14, No. 1: 11-28.

[6] Kramar, M., Isaković, T., and Fischinger, M., 2012. Seismic collapse risk of precast industrial buildings with strong connections. Earthq Eng Struct Dyn, Vol.39, No.8: 847-868.

[7] Psycharis, I.N., and Mouzakis, H.P., 2012. Shear resistance of pinned connections of precast members to monotonic and cyclic loading. Eng Struct, Vol. 41: 413-427.

[8] Negro, P., Bournas, D.A., Molina, F.J., 2013. Pseudodynamic tests on a full-scale 3-storey precast concrete building: global response. Eng Struct, Vol. 57: 594-608.

[9] Dal Lago, B., Negro, P., and Dal Lago, A., 2018. Seismic design and performance of dry-assembled precast structures with adaptable joints. Soil Dyn Earthq Eng, Vol. 106: 182-195.

[10] Dal Lago, B., Biondini, F., and Toniolo, G., 2018. Seismic performance of precast concrete structures with energy dissipating cladding panel connection systems. Structural Concrete. Vol. 19, No. 4: 1-19.

[11] Colombo, A., Negro, P., and Toniolo, G.,2014. The influence of claddings on the seismic response of precast structures: The Safecladding project. Proceedings of the 2nd European conference on earthquake engineering and seismology. Istanbul, Turkey: European Association for Earthquake Engineering (EAEE), Paper No. 1877.

[12] Ling, J., Rahman, A., Ibrahim, I., and Hamid, Z., 2012. Behavior of grouted pipe splice under incremental tensile load. Construction and Building Materials, Vol. 33: 90-98

[13] Haber, Z. B., Saiidi, M. S., and Sanders, D. H., 2014. Seismic performance of precast columns with mechanically spliced column-footing connections. ACI Structural Journal. Vol. 111, No. 3: 639-650.

[14] Hosseinin, S. J. A. and Rahman, A. B. A., 2016. Effects of spiral confinement to the bond behavior of deformed reinforcement bars subjected to axial tension. Engineering Structures, Vol. 112: 1-13

[15] Hosseini, S. J. A., Rahman, A. B. A., Osman, M. H., Saim, A., and Adnan, A., 2015. Bond behavior of spirally confined splice of deformed bars in grout. Construction Building Material, Vol. 80: 180-194. 


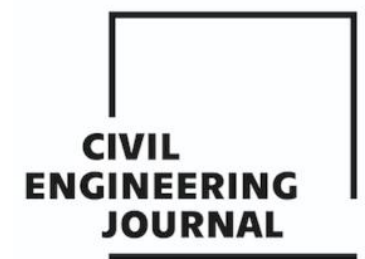

Article no. 46

THE CIVIL ENGINEERING JOURNAL 3-2021

[16] Seo, S. Y., Nam, B. R., and Kim, S. K., 2016. Tensile strength of the grout-filled head-splice sleeve. Construction and Building Materials, Vol. 124: 155-66

[17] Rave-Arango, J., Blandon, C., Restrepo, J., and Carmona, F., 2018. Seismic performance of precast concrete column-to-column lap-splice connections. Engineering Structures, Vol. 172: 687-699

[18] Gu, Q., Dong, G., Wang, X., Jiang, H., and Peng, S., 2019. Research on pseudo-static cyclic tests of precast concrete shear walls with vertical rebar lapping in grout-filled constrained hole. Engineering Structures, Vol. 189: 396-410.

[19] Tullini, N. and Minghini, F., 2016. Grouted sleeve connections used in precast reinforced concrete construction-Experimental investigation of a column-to-column joint. Engineering Structures, Vol. 1279: 784803

[20] Huang, Y., Zhu, Z., Naito, C., and Yi, W., 2017. Tensile behaviour of half grouted sleeve connections: experimental study and analytical modeling. Construction and Building Materials, Vol. 152: 96-104

[21] Jansson, P., 2008. Evaluation of grouted-filled mechanical splices for precast concrete construction. Report No R-1512, Michigan Department of Transportation, Lansing, MI, USA.

[22] Chen, J. and Xiao, Y., 2016. Experimental study on seismic behavior of precast concrete column with longitudinal reinforcement grouting-anchoring connections. China Civil Engineering Journal, Vol. 49, No.5: 111

[23] ACl 318., 2011. Building code requirements for structural concrete, Farmington Hills, MI, USA.

[24] Belleri, A. and Riva, P., 2017. Seismic performance and retrofit of precast concrete grouted sleeve connections. PCl Journal, Vol. 57, No. 1: 97-109

[25] Jiang, H., Zhang, H., Liu, W., and Yan, H., 2011. Experimental study on plug-in filling hole for steel bar anchorage of the PC structure. Journal of Harbin Institution Technology, Vol. 43, No. 10: 28-31

[26] Seifi, P., Henry, R., and Ingham, J., 2016. Panel connection details in existing New Zealand precast concrete buildings. Bulletin of the New Zealand Society for Earthquake Engineering, Vol. 49, No.2: 190-199.

[27] Riva, P., 2006. Seismic behaviour of precast column-to-foundation grouted sleeve connections.

Advances in Engineering Structures, Mechanics \& Construction, Springer, Dordrecht, Netherlands, pp. 121128.

[28] Kim, Y., 2000. A study of pipe splice sleeves for use in precast beam-column connections, PhD thesis, University of Texas at Austin, Austin, USA.

[29] Pandey, G. R. and Mutsuyoshi, H., 2005. Seismic performance of reinforced concrete piers with bond-controlled reinforcements. ACI Structural Journal, Vol. 102, No. 2,: 295-304

[30] Wu, Y., Xiao, Y., and Anderson, J., 2009. Seismic behavior of PC column and steel beam composite. Journal of Structural Engineering, Vol. 135, No. 11: 1398-1407

[31] JGJ101-2015., 2015. Specification for seismic test of buildings, China Plan Press, Beijing, China.

[32] Yan, Q., Chen, T., and Xie, Z., 2018. Seismic experimental study on a precast concrete beamcolumn connection with grout sleeves. Engineering Structures, Vol. 115: 330-44 